\title{
Performance Improvement in Noisy Image Enhancement
}

\author{
Adil Siddiqui \\ B.Tech, $3^{\text {RD }}$ YEAR \\ Inderprastha \\ Eng. College
}

\author{
Meenakshi Sharma \\ Asst. Professor \\ Inderprastha \\ Eng. College
}

\author{
Salil Khare \\ B.Tech, Inderprastha \\ Eng. College
}

\author{
Manish Zadoo \\ Asst. Professor \\ Inderprastha \\ Eng. College
}

\begin{abstract}
From the computational complexity point of view it is found that traditional image enhancement techniques used to require large no. of computations but our idea is that image smoothening can also be used as edge enhancement filters. This way of edge enhancement has specific advantage over the traditional edge enhancement filters especially in enhancing the edges of a noisy image.

The full text of the article is not available in the cache. Kindly refer the IJCA digital library at www.ijcaonline.org for the complete article. In case, you face problems while downloading the full-text, please send a mail to editor at editor@ijcaonline.org
\end{abstract}

